\title{
Mass media campaigns to promote smoking cessation among adults: an integrative review
}

\author{
Sarah Durkin, Emily Brennan, Melanie Wakefield
}

- Additional tables are published online only. To view these files please visit the journal online (http:// tobaccocontrol.bmj.com/ content/21/2.toc)

Centre for Behavioural Research in Cancer, Cancer Council Victoria, Melbourne, Victoria, Australia

\section{Correspondence to} Professor Melanie Wakefield, Director, Centre for Behavioural Research in Cancer, Cancer Council Victoria, 1 Rathdowne Street, Carlton, Victoria 3053, Australia; melanie.wakefield@ cancervic.org.au

Received 18 May 2011 Accepted 28 November 2011

\section{ABSTRACT}

Objective This review summarises the impact of mass media campaigns on promoting quitting among adult smokers overall and for subgroups; the influence of campaign intensity and different channels; the effects of different message types.

Methods The present work updates two reviews published in 2008 by searching databases using a standard search string. Articles in languages other than English were excluded, as well as letters and editorials. Screening of abstracts yielded 194 potentially relevant articles. Abstracts were evaluated by 2 authors, excluding articles that focused on populations other than adults and according to other specified criteria, resulting in 26 studies reported in 29 articles. Studies were categorised as (a) population-based studies of campaign effects and (b) studies comparing message types, using either population-based or forced exposure methods. Findings of subgroup differences for each study were noted, as well as study strengths and limitations.

Results Overall, the studies have strengthened the evidence that mass media campaigns conducted in the context of comprehensive tobacco control programmes can promote quitting and reduce adult smoking prevalence, but that campaign reach, intensity, duration and message type may influence success. Achievement of sufficient population exposure is vital, especially for lower socioeconomic status smokers, with television remaining the primary channel to effectively reach and influence adult smokers. Studies comparing different message types found negative health effects messages most effective at generating increased knowledge, beliefs, positive perceived effectiveness ratings, or quitting behaviour, while there was more mixed evidence for other message types. A few studies further suggest that negative health effects messages may also contribute to reductions in socioeconomic disparities in smoking.

Conclusions Mass media campaigns to promote quitting are important investments as part of comprehensive tobacco control programmes to educate about the harms of smoking, set the agenda for discussion, change smoking attitudes and beliefs, increase quitting intentions and quit attempts, and reduce adult smoking prevalence. Jurisdictions should aim for high reach and consistent exposure over time with preference towards negative health effects messages.

\section{INTRODUCTION}

Mass media campaigns (MMCs) have been used since the 1970 s to reduce population tobacco use. A recent review of MMCs showed that studies of MMC effects on tobacco use are more numerous than for any other health-related issue. ${ }^{1}$ Because most campaign exposure occurs incidentally during routine media use, rather than being explicitly sought out, there is high potential for widespread and repeated population exposure. ${ }^{2}$

Health communication scholars recognise there are multiple potential pathways through which MMCs could change population tobacco use. ${ }^{1} 2$ MMCs can directly influence individual decision making about quitting, as smokers view or hear campaign messages, gain new insights and reflect on the implications for their own behaviour. It is less well recognised that MMCs can also operate through indirect routes by increasing interpersonal discussion about tobacco use $\mathrm{u}^{3}$ and these discussions may themselves lead to quit attempts. Another indirect pathway is by influencing social network norms; where smoking behaviour of groups change in direct response to MMCs, this group change creates a new social network norm, ${ }^{4}$ and this new norm increases the likelihood of quitting among those wanting to join this network. ${ }^{5}$ Finally, by changing broader social norms about smoking and/or increasing interpersonal discussion of tobacco issues, MMCs can also increase the likelihood of tobacco control policy change and these policies may prompt quit attempts. ${ }^{6}$

Early empirical studies of MMC effects employed controlled field experiment designs, but this approach was no longer viable during the 1990s as large-scale MMCs became key components of comprehensive tobacco control programmes. ${ }^{7}$ Accordingly, most studies since then feature evaluations that lack control groups and seek to parse effects from concurrent population-based tobacco control policies. ${ }^{7}$ In this review, we summarise findings from recent key reviews of tobacco control MMCs and update them with recent empirical studies. We focus on adult smokers rather than adolescents, because quitting in adults confers the most rapid health and economic benefits for jurisdictions. ${ }^{8}$ We attend particularly to broadcast intensity and duration and effectiveness of different media channels. We also examine message features that influence campaign effectiveness and summarise findings about subgroup responsiveness.

\section{METHODS}

We replicated search terms used in the National Cancer Institute's (NCI) review of the effectiveness of tobacco control media interventions, which included studies published between 1970 and May 2007.' We searched databases PubMed, PsycInfo, Web of Science, Scopus and Embase from May 2007. Search terms included (tv OR television OR radio OR broadcast* OR mass media OR advertis* OR marketing OR countermarketing) AND 
(prevent* OR cessation OR initiat*) AND (tobacco OR smoking). Articles in languages other than English and letters and editorials were excluded. ${ }^{7}$ Search alerts established for each of the databases ensured that potentially relevant articles published up to July 2011 were also eligible for inclusion.

The initial search identified 942 articles. With a focus on identifying review articles and original studies that assessed the impact of tobacco control mass media interventions among adult smokers, an initial review of the titles (and abstracts, if required for clarification) of these articles by 1 of the authors (EB) identified 194 articles that were potentially relevant to the current review. The abstracts of these articles were then evaluated against the inclusion criteria specified in box 1 by 2 of the authors (EB and SD), resulting in 27 articles being identified as eligible for inclusion, with an additional 2 articles identified during manuscript preparation, for a total of 29 articles reporting the findings of 26 studies. For population-based studies we excluded post-campaign only surveys, which present a far weaker design compared with others that include pre-campaign assessments. Studies of quitline calls are most instructive for, and were therefore considered only in our examination of, differences in the impact of message types, media channels and population subgroups, rather than as a measure of overall campaign success. As previous reviews have not examined issues of campaign decay, intensity and duration, relevant studies published prior to and after May 2007 were included in that section.

This review provides a narrative synthesis of the findings from previous key reviews and empirical studies identified in the literature search. Study design, sample, campaign descriptions and overall findings pertinent to all original studies that addressed population-level effects are provided in table 1, while more detail and descriptions of subgroup differences and strengths and weaknesses are available in online table 1 (please visit the journal online at http://tobaccocontrol.com). Study design, sample, message types examined and overall findings pertinent to all original studies that examined the effectiveness of different message types are provided in table 2, while more detail and descriptions of subgroup differences and strengths and weaknesses are available in online table 2.

\section{RESULTS}

\section{Population-level effects of mass media campaigns on adult} smoking

While there are older reviews ${ }^{38-42}$ of MMC effects on smoking behaviour, recent reviews on youth smoking effects ${ }^{43} 44$ and broader reviews of MMCs across health behaviours, ${ }^{1}{ }^{4}$ we focused on the two most recent in-depth reviews of campaign effects on adult smoking. ${ }^{75}$ A Cochrane review examined a total of $11 \mathrm{MMCs}$, investigated in 58 research studies that employed controlled trial designs. ${ }^{45}$ The authors concluded that comprehensive tobacco control programmes that include MMCs can positively change smoking behaviour in adults, but noted studies were heterogeneous in their methodological design and quality. ${ }^{45}$ They further concluded that intensity and duration of MMCs may influence effectiveness, but length of follow-up and concurrent secular trends made this difficult for these reviewers to quantify.

A NCI review in 2008 was more comprehensive in its inclusion criteria, embracing controlled field experiments and population-based studies as part of comprehensive tobacco control programmes. ${ }^{7}$ This review therefore included more evaluations of the large-scale campaigns of more recent years. Although these interventions are 'messy' and difficult to evaluate, they

\section{Box 1 Inclusion criteria for studies considered in the review}

Overall inclusion criteria:

- Measure the effectiveness of a tobacco control mass media intervention among adults aged 18 years and older, using a sample containing at least some current smokers.

- Employ mass media channels such as television, radio, print and/or outdoor advertising where exposure is incidental or involuntary (ie, rather than digital media channels which often require users to 'opt in' to be exposed).

- Measure the effectiveness of messages specifically targeted at encouraging smokers to quit (ie, excluding evaluations of informational campaigns about secondhand smoke regulation).

- Present quantitative data relating exposure to mass media message/s to a measured outcome indicative of campaign impact (including message recall or recognition; cognitive and emotional advertising responses; physiological arousal; knowledge of tobacco-related health effects; tobacco-related beliefs; approval for tobacco control policies; quitline calls; and quitting-related intentions, activity and behaviour).

Additional inclusion criteria for section on population-level effects and decay, intensity and duration:

- Population studies only.

- Measure outcomes at more than one point in time (ie, pre/post or multiple post-campaign measures).

- Measure an outcome other than calls to a quitline.

Additional inclusion criteria for section on effectiveness of different media channels:

- All population and forced-exposure studies that include an explicit comparison of the effectiveness of messages delivered by two or more advertising media channels (ie, television, radio, print, outdoor).

Additional inclusion criteria for section on effectiveness of different message types:

- All population and forced-exposure studies that include an explicit comparison of the effectiveness of two or more cessation messages with different themes, characteristics or execution styles.

Additional inclusion criteria for section on subgroup differences:

- All studies eligible for inclusion in the population-level effects section that includes an explicit comparison of campaign effects by specified individual characteristics (socioeconomic status, gender, age).

- All studies eligible for inclusion in the effectiveness of different message types section that also examine effects of different message types across specified individual characteristics (socioeconomic status, gender, age). 


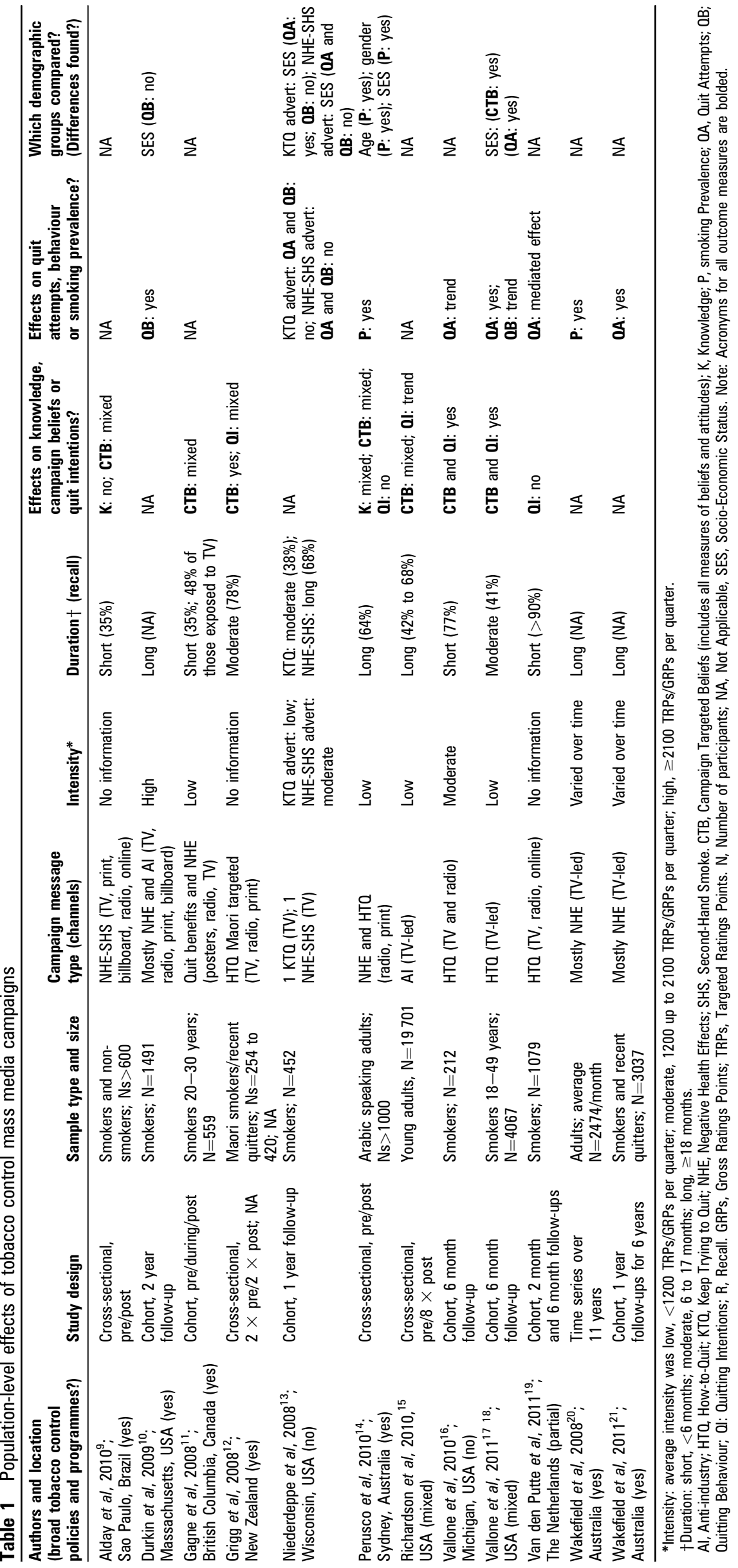




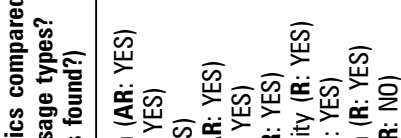

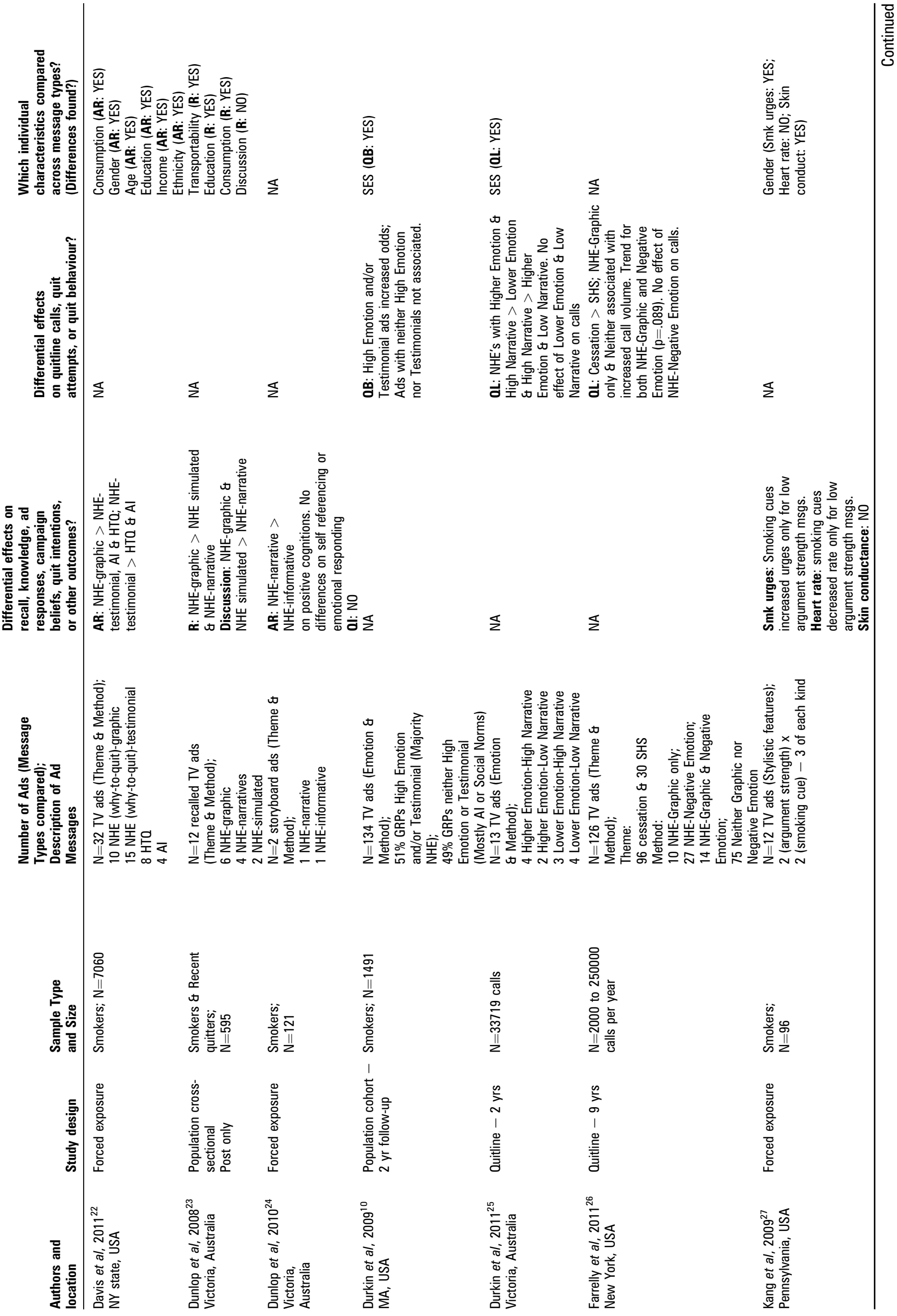




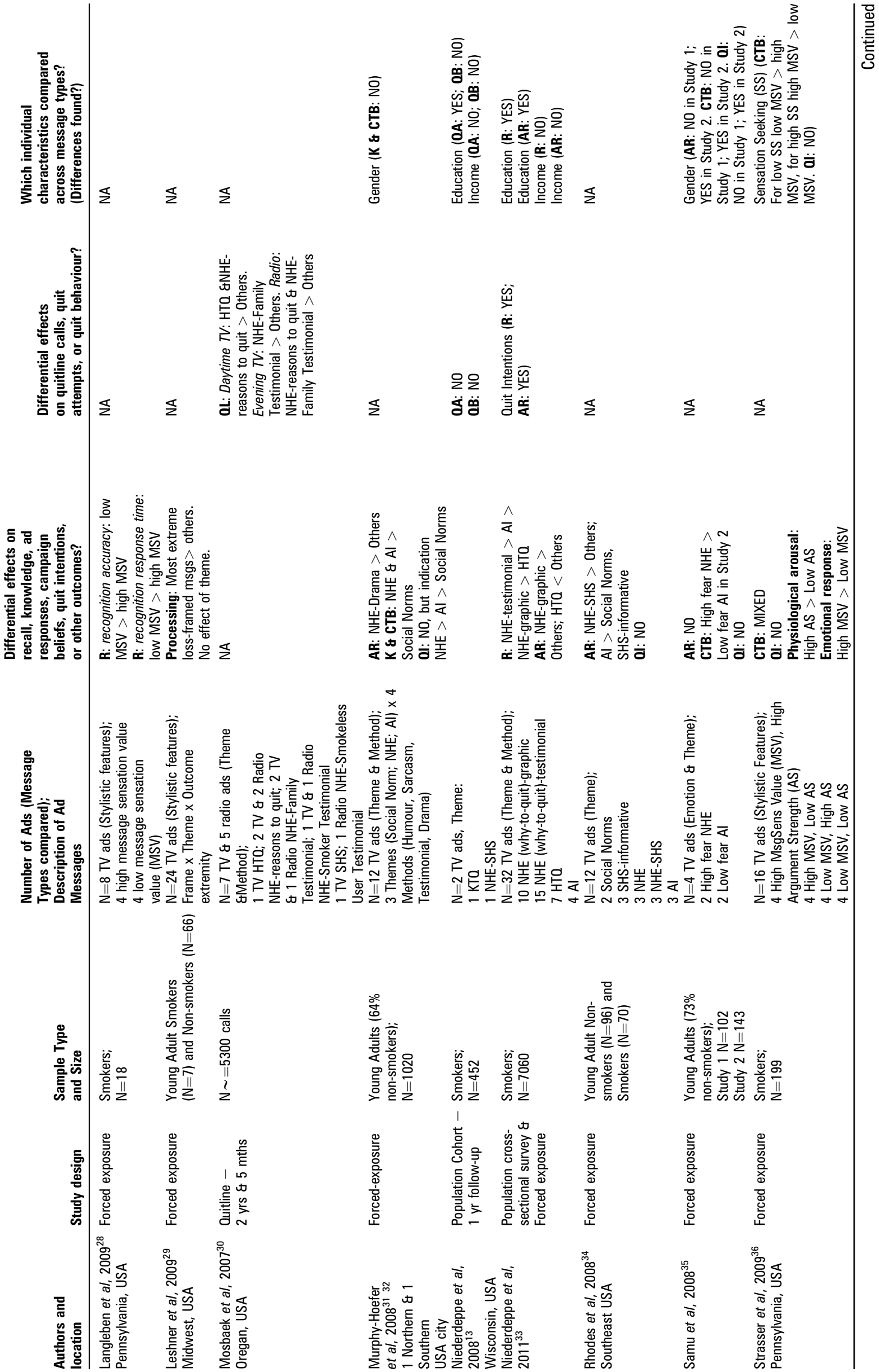




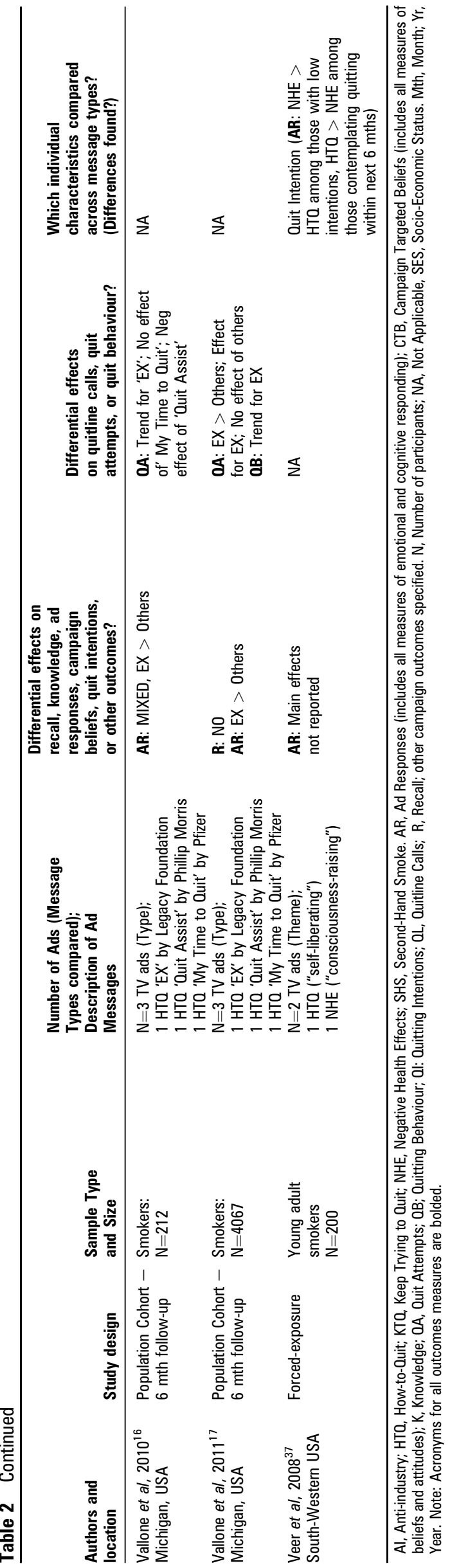

represent a better test of the intended population-based scale of MMCs, with greater levels of exposure than campaigns of earlier years. $^{2}$ Of 10 controlled field experiments promoting smoking cessation, 7 showed some evidence for an effect on reducing smoking behaviour. Of nine field experiments, eight showed positive benefits of campaigns on quitting. Of 11 populationbased government-funded MMCs that occurred as part of state or national tobacco control programmes, all demonstrated positive effects on smoking prevalence and/or per capita tobacco consumption. ${ }^{7}$

Several more recent empirical studies of specific MMCs have shown mixed support for MMC effects on knowledge, beliefs or intentions (table 1). In a series of large cross-sectional surveys, confirmed awareness of at least one 'truth' television advert (aired at low to moderate intensity over 4 years) was associated with five of nine anti-smoking beliefs and stronger desire to quit completely. ${ }^{15}$ A longitudinal evaluation of a moderate intensity 5 -week campaign emphasising the benefits of cessation found modest improvements in attitudes towards the adverse impacts of smoking among young adults, compared with those in a noncampaign area. ${ }^{11}$ A MMC aimed at Maori smokers and recent quitters in New Zealand found 54\% reported the campaign made them more likely to quit, but no change in quit intentions was observed before versus after the campaign. ${ }^{12}$ A 21-day campaign in Brazil communicating the harm of secondhand smoke produced improvements in some, but not all, campaigntargeted beliefs. ${ }^{9}$ Although some positive effects were found in each of these studies, they only measured change in attitudes and intentions, rather than actual quitting associated with exposure to MMCs.

Recent evaluations that have examined quit attempts or sustained quitting, mostly provide further support for MMC effects (table 1). One pilot study and a large national evaluation both employed a cohort design to examine the effects of confirmed recall of the low to moderate intensity 'EX' campaign among smokers. The small pilot study found a trend for effects on quit attempts, but had limited power to detect effects on this behaviour. The larger national study found a significant increase in quit attempts and a trend towards higher quit rates at follow-up. ${ }^{16}{ }^{17} \mathrm{~A}$ three-wave cohort study conducted before, during and after a 5-month national campaign encouraging and supporting cessation in The Netherlands found discussion about campaign adverts prompted discussions about quitting, which subsequently predicted quit attempts. ${ }^{19}$ A cohort study found confirmed recall of two specific advertising campaigns (keep trying to quit; dangers of secondhand smoke) aired at low to medium intensity was not associated with quit attempts or 1-year cessation, although it had limited power to detect effects on quitting behaviour. ${ }^{13} \mathrm{~A}$ cross-sectional study reported beneficial effects of a localised MMC for Arabic-speaking smokers on reducing Arabic smoking prevalence, compared with non-Arabic smoking prevalence. ${ }^{14}$

Three more comprehensive recent studies have attempted to overcome the limitations of lack of a control group and lack of power to detect quitting outcomes. These studies use natural experimental designs that exploit geographic and temporal variation in extent of cumulative population exposure to televised national and/or state MMCs, as measured by advertising rating points (gross ratings points (GRPs) and targeted ratings points (TRPs); GRPs are a standard advertising industry measure of campaign reach $\times$ frequency; for example, 1000 GRPs per quarter equates to, on average, $100 \%$ of those within a region exposed to 10 adverts, or $50 \%$ exposed to 20 adverts and so on). A time series analysis of monthly smoking prevalence over an 
11-year period found greater population exposure to televised MMCs (increase of 390 GRPs 2 months earlier) was associated with acceleration in the decline in adult smoking prevalence ( $0.3 \%$ percentage point drop), after adjusting for variation in tobacco prices, smoke-free restaurant laws, tobacco marketing restrictions and availability of smoking cessation products. ${ }^{20}$ In a population cohort study, greater population exposure to televised MMCs (average 853 GRPs per month over 2 years) was associated with a higher likelihood of quitting at a 2-year followup (odds increased 11\% for every 1000 GRPs). ${ }^{10}$ Another cohort study conducted over 6 years, found every 1000 GRPs in the 3month period prior to follow-up, increased the odds of making a quit attempt by $11 \%{ }^{21}$ These studies of the effects of multiple campaigns over time indicate campaigns can generally expect small effect sizes (requiring large samples to detect), but because they involve mass numbers of individuals within a population, the degree of change is of high practical significance, helping to drive down population smoking prevalence by increasing successful quitting rates.

Since the last reviews of 2008 concluded that MMCs have beneficial effects, five of eight additional studies examining effects of MMCs on behaviour (quit attempts, sustained quitting or smoking prevalence) found beneficial effects, one found a mediated effect, one found a trend towards an effect and one did not find any effects. Of the additional four evaluations that only measured campaign-targeted knowledge, beliefs and/or quitting intentions, some positive findings were also observed for each campaign. Overall, these studies further strengthen the evidence that MMCs can improve attitudes and intentions, promote quitting and reduce adult smoking prevalence. Some mixed findings indicate not all campaigns are equally successful, and factors including the reach, intensity, duration and type of messages used are likely to determine overall impact.

\section{Campaign decay, intensity and duration}

An important aspect of determining optimal campaign investment is campaign decay, or the extent to which effects are detectable after the campaign broadcast ends. ${ }^{46}$ Although some consumer product advertising may be recalled long after broadcast ends, most advertising primarily has effects on product sales during broadcast and for a short time following. ${ }^{46}$ These effects have also been observed in tobacco control MMCs. A recent cohort study ${ }^{21}$ found quit attempts were associated with MMCs in the most recent 3 months, but not with exposure in earlier months. A time-series analysis showed the beneficial effect of MMCs on smoking prevalence lasted only up to 2 months after exposure. ${ }^{20}$ One reason that withdrawal of MMCs leads to decay of effects is because tobacco-promoting influences, such as tobacco marketing and tobacco addiction, gradually regain precedence. Sustained smoking behaviour change requires frequent longer-term campaign exposure.

Few studies have considered the intensity of campaign investment that can most efficiently achieve population changes. Hyland and colleagues ${ }^{47}$ found an average of 700 GRPs per quarter was only weakly associated with quitting. A more recent cohort study of adult smokers found a mean of 2560 GRPs per quarter was significantly associated with quitting. ${ }^{10}$ A time-series analysis found an average of 1200 GRPs each quarter was significantly associated with reduced smoking prevalence. ${ }^{20}$ Taken together, these findings suggest that, at least in highincome countries, an average of 1200 GRPs per quarter for a total of 4800 GRPs per year are needed to reduce adult smoking prevalence, although 2560 GRPs per quarter (total of 10240 GRPs per year) could be expected to reap proportionally larger returns.
Greater advertising exposure may be required to influence adult than youth smoking, due perhaps to the fact that most adult smokers are hampered by addiction. For comparison, a threshold for detecting beneficial effects for reducing smoking uptake among youth may exist around 300 teenage-targeted GRPs per quarter, ${ }^{48}$ with effects increasing linearly ${ }^{48-50}$ until potentially beginning to diminish above 1250 GRPs per quarter. ${ }^{49}$

\section{Effects of MMCs on demographic subgroups}

In contrast to producing general audience adverts that convey messages of relevance to most adult smokers, targeting tobacco control adverts to specific audience groups (eg, age, gender, education, ethnicity) may increase message relevance and persuasion. However, this strategy may also increase costs, as multiple adverts are required. Given finite resources, targeting messages may result in a lower proportion of funds available to broadcast these different adverts, resulting in lower rates of exposure. The extent of targeting and segmentation therefore needs to be weighed carefully against the importance of maximising campaign exposure. Research among adolescents reported in the NCI review ${ }^{7}$ found few differences between different demographic groups' responses to MMCs, that advert characteristics were more important than demographic characteristics, concluding that adverts that perform well do so among many population groups.

To examine these issues among adult smokers, we compared demographic subgroup differences in response to MMCs reported in previous reviews and more recent studies (online table 1). In the review by Bala and colleagues, ${ }^{45}$ two widereaching campaigns examined effects separately for different socioeconomic status (SES) groups (education and ethnicity) and campaign effectiveness did not differ by education or ethnicity. Another review of MMC effectiveness among socioeconomically disadvantaged populations, ${ }^{51}$ suggested that differences in the effectiveness of MMCs between SES groups may be due to differences in meaningful exposure, or motivational response, or opportunity to sustain cessation in the long term. Of the nine reviewed general population campaigns that were less successful among lower SES smokers, five suffered from low levels of exposure and promotion. ${ }^{52-57}$ Of the other four higher reach campaigns, two were less effective in generating quitline calls in lower SES, ${ }^{58} 59$ while the other two campaigns showed equal effects across SES in motivating quitline calls, but SES differences occurred in translating these attempts into success. ${ }^{60} 61$ In contrast, nine other reviewed general population campaigns showed equal ${ }^{62-67}$ or greater effects on motivational response and/or long-term cessation in lower SES groups, and all nine of these achieved sufficient exposure. ${ }^{68-70}$ This review ${ }^{51}$ also identified 13 MMCs that specifically targeted low SES populations. Underscoring the importance of adequate exposure and campaign reach, the five targeted campaigns that were not successful, were hampered by limited reach, ${ }^{71-73}$ or very low levels of recall. ${ }^{7475}$ The other eight campaigns showed mixed findings. ${ }^{76-83}$

Three more recent population-level studies have reported effects separately by SES. An examination of high intensity televised MMCs found no significant interaction between total potential exposure to MMCs and quitting behaviour 2 years later across SES groups. ${ }^{10}$ A recent evaluation of a non-televised campaign, ${ }^{14}$ found a significant reduction in smoking prevalence in the highest SES group, but not in moderate or low SES groups. A cohort study of the 'EX' campaign found campaign awareness was associated with increased quit attempts among non-Hispanic black smokers, but not among Hispanics 
(or non-Hispanic white smokers), and among smokers with less than high school education, but also showed a positive trend $(p=0.08)$ among those with most education. ${ }^{18}$ This campaign was aired at low intensity overall, but placement was targeted to media programmes and channels consumed by lower income and blue collar smokers of diverse race/ethnicity. The clear effects on lower SES smokers for the widely broadcast televisionled campaigns ${ }^{1045} 51$ versus the negative and mixed effects of low-reach general population campaigns and low-SES targeted campaigns, ${ }^{14} 1851$ indicates that general population campaigns of at least moderate intensity and duration are effective for motivating quitting in lower SES groups. However, this strategy is likely to produce equivalent effects across SES groups, rather than greater effects in lower SES groups.

Examining differences by age and gender, Bala and colleagues $^{45}$ found three studies that showed long-term MMC effects for men and one for women, while three found MMC effects among younger smokers and another three found MMC effects among older smokers. A recent non-televised campaign, ${ }^{14}$ found a significant reduction in prevalence in males but not females and among those aged 40 years or older, but not in those aged 18-39 years. Overall, given only one additional study addressing demographic subgroups, we defer to the conclusion of Bala and colleagues ${ }^{45}$ that campaign effectiveness does not consistently differ by gender and age.

\section{Effectiveness of different channels of delivery of mass media campaigns}

Few studies have examined the relative effectiveness of different advertising channels. The NCI review ${ }^{7}$ of $47 \mathrm{MMCs}$ found $98 \%$ used television, $94 \%$ radio, $89 \%$ print and $87 \%$ billboards. Only two reviewed studies examined comparative effects of different media types, finding television adverts were recalled by twice as many respondents as radio adverts. This review highlighted another US national adult population survey which found television provides the greatest exposure among smokers, and that smokers are more likely to be heavier users of television and radio and less likely than non-smokers to be magazine or newspaper readers. ${ }^{84}$

Since the NCI review, two studies have examined the relative effectiveness of different MMC channels on quitline calls. Farrelly and colleagues ${ }^{85}$ found for each $10 \%$ increase in expenditure on television, radio and newspaper advertising, calls increased by $1.51 \%, 0.037 \%$ and $0.022 \%$ respectively, with the latter only a marginally significant association. Mosbaek and colleagues $^{30}$ examined a range of different adverts aired on television and on radio and found the 10 most cost effective adverts were aired on television, while the most cost effective radio advert was ranked 11 th overall. It is difficult to determine whether the reduced effectiveness of non-televised messages is due to the channel, to lower population reach, or to differences in message effectiveness.

One recent study found a MMC message broadcast on radio generated similar levels of concern about smoking and motivation to quit as a similar message shown on television. ${ }^{86}$ Although this study indicates radio messages can be effective, it was broadcast concurrently with a televised version of the campaign, and so part of its effectiveness may be due to smokers bringing to mind the images associated with the televised advert. Future research should examine the effects of a standalone radio campaign. Despite radio's lower costs its reduced population reach means that it is unlikely to be a good substitute for television in influencing population-wide smoking, and could be considered a reinforcing adjunct.

\section{Effectiveness of different types of mass media messages}

MMC messages differ in informational content (theme), purpose (why-to-quit vs how-to-quit), method, emotional tone and stylistic features. ${ }^{7} 13338788$ The NCI review identified four studies that explicitly addressed the effectiveness of different messages among adult smokers. ${ }^{7}$ One ${ }^{89}$ examined results from a collection of focus tests, concluding that anti-industry and secondhand smoke (SHS) messages were most effective; however, this study was criticised for lacking a transparent criteria for the definition of effectiveness. ${ }^{7} 89$ The other three studies demonstrated that messages which elicited negative emotions by describing the serious health consequences of smoking scored higher on memorability ${ }^{90}$ and ratings of perceived effectiveness ${ }^{91}$ and were more likely to be recalled by recent quitters who believed that anti-smoking advertisements had contributed to their quit attempt. ${ }^{62}$ Our search identified 6 new population studies, 3 quitline studies and 11 forced-exposure studies that compared the effectiveness of different message characteristics, including comparisons of message themes (negative health effects, how-to-quit, anti-industry, social norms, information about SHS regulations), methods (graphic depictions, medical simulations, testimonials, narratives, information), emotional tone (high vs low emotion) and inclusion of specific stylistic features (outcome extremity, message sensation value, argument strength, smoking cues) (table 2). In this review negative health effects (NHE) messages are those that emphasise the serious health effects of smoking for the individual and/or their family or friends, and include those previously described as 'health effects', 'why-to-quit', 'reasons to quit', 'family testimonial', 'smoker testimonial' and 'dangers of SHS'.

Four studies examined the impact of inclusion of specific stylistic features, including outcome extremity, message sensation value (MSV), argument strength and presence or absence of smoking cues on campaign outcomes. ${ }^{27-29} 36$ One forced-exposure study found better performance on a recognition task and on psychophysiological measures of central cognitive processing after exposure to more extreme loss-framed messages than after exposure to less extreme and gain-framed messages. ${ }^{29}$ One study identified an advantage for low MSV on accuracy and response time, ${ }^{28}$ while another forced-exposure study found the impact of MSV on self-efficacy and beliefs depended on the sensation seeking level of participants. ${ }^{36}$ This study also found there was no effect of argument strength on beliefs and intentions. ${ }^{36}$ One other study found smoking cues increased urges to smoke and caused larger decreases in heart rate (potentially indicating an orienting response), but only when argument strength was low. ${ }^{27}$

Overall, two population, ${ }^{10} 13$ two quitline studies ${ }^{26} 30$ and four forced exposure studies reported in six articles ${ }^{22} 31-35$ compared the effectiveness of NHE messages to other message themes (social norms; anti-industry; how-to-quit). The two quitline studies found some specific NHE messages were as, or more effective than some specific how-to-quit messages, but other NHE messages were less effective. All four of the forcedexposure studies $^{22} 31-35$ found NHE messages were more effective than how-to-quit, anti-industry and/or social norms themes at generating either increased knowledge, positive beliefs, perceived effectiveness ratings or motivation to quit. No studies that examined effects on quit intentions found differences between message themes ${ }^{31} 323435$ however, these four studies included a majority of non-smokers in their samples and so were underpowered to detect effects on smokers' quitting intentions. There was also evidence from one large population study that 
high emotion or testimonial adverts (majority of which were NHE messages) were more effective than comparison adverts at increasing quitting rates. ${ }^{10}$ The other population study found neither a NHE-SHS message nor a keep-trying-to-quit message increased quit attempts or sustained quitting, however this study had limited power to detect changes in quitting behaviour. $^{13}$

Overall these findings provide good support for the use of NHE messages, comparatively less support for how-to-quit and anti-industry messages, and an indication that more work is required to determine the importance of stylistic features, such as MSV and the inclusion of smoking cues. As discussed in the NCI review, untangling the effective elements of NHE messages remains difficult because of the tendency for particular elements (for example, the NHE information, using a graphic and/or testimonial format, and high levels of negative emotions) to co-occur. $^{7}$

A number of recent studies have attempted to disentangle the key effective elements of NHE adverts. Examining different types of NHE messages separately, one study found those messages that included neither graphic images nor negative emotion (typically how-to-quit adverts) and those with graphic images only were associated with increased quitline calls, while there was a trend for those including graphic images and negative emotion to be associated ( $p=0.089$ ), but those with negative emotion only did not increase calls. ${ }^{26}$ However, unlike other research which has used smokers to rate the level of emotion in adverts ${ }^{102591}$ this study had coders rate adverts in terms of the strength of emotion they expected would be elicited from smokers. In contrast, another study ${ }^{25}$ using an independent smoker rating of advert emotion level, found that NHE messages that generated high levels of emotion and/or had narrative elements drove greater quitline calls, while there was no effect of airing low emotion non-narrative NHE messages. Similarly, a large population cohort study found those adverts that did not generate high emotion or include personal stories were not associated with sustained quitting. ${ }^{10}$ Further research on the relative effectiveness of the level of emotion and narrativity of NHE messages is required, and should also explore whether the use of emotion and story-based messages might explain the more successful how-to-quit and anti-industry messages.

\section{Effectiveness of different message types by demographic subgroups}

A number of population and forced-exposure studies specifically explored message characteristics that might be most effective for lower SES smokers (online table 2). A population study found baseline recall of 'keep-trying-to-quit' adverts was associated with lower probability of making a quit attempt among those with high school or less education, but with a greater probability among higher educated smokers. ${ }^{13}$ In contrast, there was no interaction between education level and baseline recall of an NHE-SHS advert. Another study ${ }^{10}$ found exposure to high emotion and/or personal testimonial adverts was associated with quitting at 2-year follow-up for mid, and to a lesser extent for low SES smokers, but not for high SES smokers. A large forced-exposure study ${ }^{33}$ found differences in perceived effectiveness between NHE adverts and how-to-quit adverts were more pronounced among lower educated smokers compared to higher educated smokers. Greater increases in quitline calls from lower SES groups were also observed in one study ${ }^{25}$ when high emotion testimonial NHE messages were aired, and this advantage was evident but not as strong among higher SES groups.
Two studies have explored whether males and females and smokers of different age groups respond in similar ways to different message characteristics. A large forced-exposure study $^{22}$ found few age and gender differences in responses to different adverts (online table 2). Another forced-exposure study found no gender effects on message-targeted knowledge or beliefs. $^{32}$

The literature examining differences in the effectiveness of various message types among different SES groups indicates that widespread broadcast of NHE messages using testimonials or graphic depictions may work well across population groups and may contribute to reductions in disparities between high SES smokers and smokers with some degree of disadvantage. Research should examine whether these types of messages can reduce disparities between smokers with greater degrees of disadvantage. There is some evidence that some messages may increase SES disparities in smoking (how-to-quit; keep trying to quit) ${ }^{13} 33$ however more research is required. Examinations of the effectiveness of different message types across age and gender revealed no consistent patterns of effects.

\section{CONCLUSIONS AND LESSONS FOR PRACTICE}

There is strong empirical evidence that, within the context of comprehensive tobacco control programmes, MMCs can promote adult quitting and reduce adult smoking prevalence. Effectiveness may depend upon campaign reach, intensity, duration and the messages used. Campaigns require ongoing investment to sustain a level of at least $1200 \mathrm{GRPs}$ per quarter for a total of 4800 GRPs per year. Sufficient population exposure is crucial: television remains the primary channel to reach most smokers. Higher MMC exposure also appears to confer greater benefit on socioeconomically disadvantaged population subgroups. Head-to-head comparative studies of message themes find that NHE messages, many of which feature graphic imagery and/or testimonial stories and elicit negative emotions, tend to perform well, compared with messages without such features. It remains difficult to disentangle the elements that drive observed effects since these message features so frequently co-occur; however, strong emotion activation and narrative or testimonial style may be important. In general, these kinds of messages may be especially beneficial for low and mid SES populations; there is no consistent evidence that these messages perform differently in various age and gender groups.

Although funders often balk at the upfront costs of campaign investment, MMCs have a low cost per capita because of their potential for very high population reach. In simulation studies, $\mathrm{MMC}$-attributable accelerations of the decline in smoking prevalence translate into substantial cost savings in terms of premature deaths averted and healthcare costs saved. ${ }^{92-94}$ A costeffectiveness study illustrated that benefits substantially increase over the remaining lifetime of quitters. ${ }^{95}$ Most studies of MMC benefit are from high-income countries, so a challenge for the future is to ensure the application of effective tobacco control MMCs in low-income and middle-income countries. ${ }^{9} 9697$

Several strategies can improve MMC efficiency and optimise effects. Buying media to ensure the bulk of smokers in the population can be exposed is critical, ${ }^{84}$ while specific targeting of small population subgroups using a mass reach strategy is less efficient. Choosing NHE messages may maximise efficiency, although even campaigns with the highest impact messages cannot be effective unless they reach a sufficient percentage of the population over time. Adapting and recycling messages already used successfully in other jurisdictions can avoid the 


\section{What this paper adds}

This review found the latest population studies have strengthened the evidence that mass media campaigns conducted in the context of comprehensive tobacco control programs can promote quitting and reduce adult smoking prevalence, but that campaign reach, intensity, duration and message type influence success. Sufficient population exposure was vital for impact, especially among low socioeconomic status smokers.

- Negative health effects messages were most effective at generating increased knowledge, beliefs, positive perceived effectiveness ratings, or quitting behaviour, while there was more mixed evidence for other message types. There was also some evidence that negative health effects messages may be especially effective for low socio-economic status smokers.

- These findings strengthen existing evidence that mass media campaigns to promote quitting are important investments as part of comprehensive tobacco control programs to reduce adult smoking prevalence.

substantial costs of campaign development, as long as these messages pre-test well locally. ${ }^{98} 99$ Finally, MMCs may perform optimally when there is less competition from tobacco marketing (such as price discounting and promotion of attractive tobacco imagery). Implementing comprehensive restrictions on tobacco marketing will enhance the context for MMC effectiveness. Consideration should also be given to harnessing the potential synergies between MMCs and other tobacco control policies. ${ }^{100}$

The changing media environment poses challenges to achieving adequate exposure to planned media messages; as more channels emerge, the clutter of competing messages increases and consumers gain greater control over message exposure. We excluded campaigns relying on newer digital technologies, since these often require an 'opt-in' choice by individuals to be exposed by purposefully clicking on a web link or opening a text message. This non-incidental avenue for exposure means that population reach is more limited. Understanding how broadcast media can coordinate with newer technologies, such as website downloads and interactive games, cell phone applications and expert systems is critically important. ${ }^{4}$ Studies are needed that examine the impact of purposive avoidance or active discounting of NHE messages, given that avoidance of graphic health warnings on cigarette packs predicts subsequent quit attempts. ${ }^{101}$ There is also growing interest in understanding neural responses to advertising messages. Functional MRI can detect neural responses to persuasive messages at the moment of exposure. ${ }^{28} 102$

The majority of studies have examined the direct effects of campaign exposure on smokers' beliefs and behaviours. However, a growing body of literature has been focused on campaign-generated interpersonal discussion. ${ }^{3} 1923103104$ This is important since such interaction can amplify campaign effects by extending the reach of the campaign to those not directly exposed, and by facilitating deeper message processing among those who have. In addition, few studies have examined how MMCs affect tobacco policy change, although MMCs have been used to publicise forthcoming legislation (eg, Alday et al and Chang et $a l^{9}{ }^{105}$ ).
Policymakers and funders concerned to implement aspects of Article 12 of the Framework Convention on Tobacco Control, ${ }^{106}$ which advocates a focus on education, communication and public awareness, should be aware that MMCs are an effective strategy for jurisdictions to educate about the harms of smoking, set the agenda for discussion, change smoking attitudes and beliefs, increase quitting intentions and quit attempts and reduce adult smoking within the framework of a comprehensive tobacco control programme.

Competing interests None.

Provenance and peer review Commissioned; externally peer reviewed

\section{REFERENCES}

1. Wakefield MA, Loken B, Hornik RC. Use of mass media campaigns to change health behaviour. Lancet 2010;376:1261-71.

2. Hornik R. Public Health Communication: Evidence for Behavior Change. Mahwah, NJ: Lawrence Erlbaum, 2002.

3. Southwell BG, Yzer MC. The roles of interpersonal communication in mass media campaigns. Communication Yearbook 2007;31:419-62.

4. Abroms LC, Maibach EW. The effectiveness of mass communication to change public behavior. Annu Rev Public Health 2008;29:219-34.

5. Christakis NA, Fowler $\mathrm{JH}$. The collective dynamics of smoking in a large social network. N Engl J Med 2008;358:2249-58.

6. Asbridge M. Public place restrictions on smoking in Canada: assessing the role of the state, media, science and public health advocacy. Soc Sci Med 2004:58:13-24.

7. National Cancer Institute. The Role of the Media in Promoting and Reducing Tobacco Use. Executive Summary. The Role of the Media in Promoting and Reducing Tobacco Use. Bethesda, MD: United States Department of Health and Human Services, National Institutes of Health, National Cancer Institute. NIH Pub. No 07-6242. 2008:iii-22.

8. Doll R, Peto R, Boreham J, et al. Mortality in relation to smoking: 50 years' observations on male British doctors. BMJ 2004;328:1519.

9. Alday J, Murukutla N, Cedillo C, et al. Smoke-free Sao Paulo: a campaign evaluation and the case for sustained mass media investment. Salud Publica Mex 2010;52:S216-25

10. Durkin SJ, Biener L, Wakefield MA. Effects of different types of antismoking ads on reducing disparities in smoking cessation among socioeconomic subgroups. Am J Public Health 2009;99:2217-23.

11. Gagne $\mathbf{L}$. The 2005 British Columbia smoking cessation mass media campaign and short-term changes in smokers attitudes. J Health Commun 2008;13:125-48.

12. Grigg M, Waa A, Kawenata Bradbrook S. Response to an indigenous smoking cessation media campaign-It's about whanau. Aust NZ J Public Health 2008;32:559-64.

13. Niederdeppe J, Fiore MC, Baker TB, et al. Smoking-cessation media campaigns and their effectiveness among socioeconomically advantaged and disadvantaged populations. Am J Public Health 2008;98:916-24.

14. Perusco A, Poder N, Mohsin M, et al. Evaluation of a comprehensive tobacco control project targeting Arabic-speakers residing in south west Sydney, Australia. Health Promot Int 2010;25:153-65.

15. Richardson AK, Green M, Xiao HJ, et al. Evidence for truth (R) the young adult response to a youth-focused anti-smoking media campaign. Am J Prev Med 2010;39:500-6.

16. Vallone DM, Duke JC, Mowery PD, et al. The impact of EX (R) results from a pilot smoking-cessation media campaign. Am J Prev Med 2010;38:S312-18.

17. Vallone DM, Duke JC, Cullen J, et al. Evaluation of EX: a national mass media smoking cessation campaign. Am J Public Health 2011;101:302-9.

18. Vallone D, Niederdeppe J, Richardson A, et al. A national mass media smoking cessation campaign: effects by race/ethnicity and education. Am J Health Promot 2011;25(5 Suppl):S38-50.

19. van den Putte B, Yzer M, Southwell BG, et al. Interpersonal communication as an indirect pathway for the effect of antismoking media content on smoking cessation. $J$ Health Commun 2011;16:470-85.

20. Wakefield MA, Durkin S, Spittal MJ, et al. Impact of tobacco control policies and mass media campaigns on monthly adult smoking prevalence. Am J Public Health 2008;98:1443-50

21. Wakefield M, Spittal M, Yong H, et al. Effects of mass media campaign exposure intensity and durability on quit attempts in a population-based cohort study. Health Educ Res 2011. Published Online First: July 2011. doi:10.1093/her/cyr054

22. Davis KC, Nonnemaker JM, Farrelly MC, et al. Exploring differences in smokers perceptions of the effectiveness of cessation media messages. Tob Control 2011;20:26-33.

23. Dunlop SM, Wakefield M, Kashima Y. The contribution of antismoking advertising to quitting: intra- and interpersonal processes. J Health Commun 2008;13:250-66.

24. Dunlop SM, Wakefield M, Kashima Y. Pathways to persuasion: cognitive and experiential responses to health-promoting mass media messages. Communication Research 2010;37:133-64. 
25. Durkin S, Wakefield M, Spittal M. Which types of televised anti-tobacco ads prompt more quitline calls from disadvantaged groups? Health Educ Res 2011;26:998-1009.

26. Farrelly MC, Davis KC, Nonnemaker JM, et al. Promoting calls to a quitline: quantifying the influence of message theme, strong negative emotions and graphic images in television advertisements. Tob Control 2011:20:279-84.

27. Kang Y, Cappella JN, Strasser AA, et al. The effect of smoking cues in antismoking advertisements on smoking urge and psychophysiological reactions. Nicotine Tob Res 2009:11:254-61.

28. Langleben DD, Loughead JW, Ruparel K, et al. Reduced prefrontal and temporal processing and recall of high "sensation value" ads. Neuroimage 2009:46:219-25.

29. Leshner G, Cheng $\mathrm{IH}$. The effects of frame, appeal, and outcome extremity of antismoking messages on cognitive processing. Health Commun 2009;24:219-27.

30. Mosbaek CH, Austin DF, Stark MJ, et al. The association between advertising and calls to a tobacco quitline. Tob Control 2007;16(Suppl 1):i24-9.

31. Murphy-Hoefer R, Hyland A, Higbee C. Perceived effectiveness of tobacco countermarketing advertisements among young adults. Am J Health Behav 2008;32:725-34.

32. Murphy-Hoefer R, Hyland A, Rivard C. The influence of tobacco countermarketing ads on college students' knowledge, attitudes, and beliefs. J Am Coll Health 2010;58:373-81.

33. Niederdeppe J, Farrelly MC, Nonnemaker J, et al. Socioeconomic variation in recall and perceived effectiveness of campaign advertisements to promote smoking cessation. Soc Sci Med 2011;72:773-80.

34. Rhodes N, Roskos-Ewoldsen DR, Edison A, et al. Attitude and norm accessibility affect processing of anti-smoking messages. Health Psychol 2008;27(Suppl 3): S224-32.

35. Samu S, Bhatnagar N. The efficacy of anti-smoking advertisements: the role of source, message, and individual characteristics. Int J Nonprofit Vol Sector Mark Special Issue: Social marketing 2008;13:237-50.

36. Strasser AA, Cappella JN, Jepson C, et al. Experimental evaluation of antitobacco PSAs: effects of message content and format on physiological and behavioral outcomes. Nicotine Tob Res 2009:11:293-302.

37. Veer $\mathbf{E}$, Tutty $\mathbf{M}$, Willemse J. It's time to quit: using advertising to encourage smoking cessation. J Strat Market 2008;16:315-25.

38. Farrelly MC, Niederdeppe J, Yarsevich J. Youth tobacco prevention mass media campaigns: past, present, and future directions. Tob Control 2003;12(Suppl 1): i35-47.

39. Wakefield M, Flay B, Nichter $\mathbf{M}$, et al. Effects of anti-smoking advertising and youth smoking: a review. J Health Commun 2003;8:229-47.

40. Wakefield $\mathbf{M}$, Flay $\mathrm{B}$, Nichter $\mathrm{M}$, et al. Role of the media in influencing trajectories of youth smoking. Addiction 2003;98(Suppl 1):79-103.

41. Snyder LB, Hamilton MA. A meta-analysis of U.S. health campaign effects on behavior: emphasize enforcement, expousre, and new information, and beware the secular trend. In: Hornik RC, ed. Public Health Communication: Evidence for Behavior Change. Mahway, NJ: Lawrence Erlbaum, 2002:357-83.

42. Global Dialogue for Effective Stop Smoking Campaigs. The Need for Effective Mass Media Public Educationn Campaigns as Part Of Comprehensive Tobacco Control Programs. 2011. http://www.stopsmokingcampaigns.org laccessed 15 May 2011).

43. Brinn MP, Carson KV, Esterman AJ, et al. Mass media interventions for preventing smoking in young people. Cochrane Database Syst Rev 2010;(11):CD001006.

44. US Department of Health and Human Services. Preventing Tobacco Use Among Young People-An update. A Report of the Surgeon general. Atlanta, GA: US Department of Health and Human Services, Centers for Disease Control and Prevention, National Center for Chronic Disease Prevention and Health Promotion Office on Smoking and Health, 1994.

45. Bala M, Strzeszynski L, Cahill K. Mass media interventions for smoking cessation in adults. Cochrane Database Syst Rev 2008;(1):CD004704.

46. Tellis GJ. Effective Advertising: Understanding When, How, and Why Advertising Works. Thousand Oaks, California: Sage Publications, Inc, 2004.

47. Hyland A, Wakefield M, Higbee C, et al. Anti-tobacco television advertising and indicators of smoking cessation in adults: a cohort study. Health Educ Res 2006;21:348-54.

48. Emery S, Wakefield M, Terry-McElrath $Y$, et al. Televised state-sponsored antitobacco advertising and youth smoking beliefs and behavior in the United States, 1999-2000. Arch Pediatr Adolesc Med 2005;159:639-45.

49. Farrelly MC, Davis KC, Haviland ML, et al. Evidence of a dose-response relationship between "truth" antismoking ads and youth smoking prevalence. Am J Public Health 2005;95:425-31.

50. Terry-McElrath YM, Wakefield MA, Emery S, et al. State anti-tobacco advertising and smoking outcomes by gender and race/ethnicity. Ethn Health 2007; 12:339-62

51. Niederdeppe $\mathbf{J}$, Kuang $X$, Crock $B$, et al. Media campaigns to promote smoking cessation among socioeconomically disadvantaged populations: what do we know, what do we need to learn, and what should we do now? Soc Sci Med 2008:67:1343-55.

52. Ossip-Klein DJ, Giovino GA, Megahed N, et al. Effects of a smoker's hotline: results of a 10-county self-help trial. J Consult Clin Psychol 1991;59:325-32.

53. Shuster GF 3rd, Utz SW, Merwin E. Implementation and outcomes of a community-based self-help smoking cessation program. J Community Health Nurs 1996;13:187-98.
54. Elder JP, Campbell NR, Mielchen SD, et al. Implementation and evaluation of a community-sponsored smoking cessation contest. Am J Health Promot 1991:5:200-7.

55. Tillgren $\mathbf{P}$, Haglund BJ, Ainetdin T, et al. Who is a successful quitter? One-year follow-up of a national tobacco quit and win contest in Sweden. Scand J Soc Med 1995:23:193-201.

56. Fortmann SP, Taylor CB, Flora JA, et al. Changes in adult cigarette smoking prevalence after 5 years of community health education: the Stanford five-city project. Am J Epidemiol 1993:137:82-96.

57. Winkleby MA, Flora JA, Kraemer HC. A community-based heart disease intervention: predictors of change. Am J Public Health 1994;84:767-72.

58. Zhu SH, Anderson CM, Johnson CE, et al. A centralised telephone service for tobacco cessation: the California experience. Tob Control 2000;9(Suppl 2): 1148-55.

59. Platt S, Tannahill A, Watson J, et al. Effectiveness of antismoking telephone helpline: follow up survey. BMJ 1997;314:1371-5.

60. An LC, Schillo BA, Kavanaugh AM, et al. Increased reach and effectiveness of a statewide tobacco quitline after the addition of access to free nicotine replacement therapy. Tob Control 2006;15:286-93.

61. Owen L. Impact of a telephone helpline for smokers who called during a mass media campaign. Tob Control 2000;9:148-54.

62. Biener L, Reimer RL, Wakefield M, et al. Impact of smoking cessation aids and mass media among recent quitters. Am J Prev Med 2006;30:217-24.

63. Warnecke RB, Langenberg $P$, Wong SC, et al. The second Chicago televised smoking cessation program: a 24-month follow-up. Am J Public Health 1992; 82:835-40.

64. Lando HA, Hellerstedt WL, Pirie PL, et al. Results of a long-term community smoking cessation contest. Am J Health Promot 1991:5:420-5.

65. Miller N, Frieden TR, Liu SY, et al. Effectiveness of a large-scale distribution programme of free nicotine patches: a prospective evaluation. Lancet 2005; 365:1849-54.

66. Siahpush M, Wakefield M, Spittal M, et al. Antismoking television advertising and socioeconomic variations in calls to Quitline. J Epidemiol Community Health 2007:61:298-301.

67. Macaskill P, Pierce JP, Simpson JM, et al. Mass media-led antismoking campaign can remove the education gap in quitting behavior. Am J Public Health 1992; 82:96-8.

68. Pierce JP, Anderson DM, Romano RM, et al. Promoting smoking cessation in the United States: effect of public service announcements on the Cancer Information Service telephone line. J Natl Cancer Inst 1992;84:677-83.

69. Secker-Walker RH, Flynn BS, Solomon LJ, et al. Helping women quit smoking: results of a community intervention program. Am J Public Health 2000;90:940-6

70. Levy DT, Mumford EA, Compton C. Tobacco control policies and smoking in a population of low education women, 1992-2002. J Epidemiol Community Health 2006;60(Suppl 2):20-6.

71. Ahijevych K, Wewers ME. Low-intensity smoking cessation intervention among African-American women cigarette smokers: a pilot study. Am J Health Promot 1995; 9:337-9.

72. Campbell MK, Tessaro I, DeVellis B, et al. Effects of a tailored health promotion program for female blue-collar workers: health works for women. Prev Med 2002;34:313-23.

73. Schorling JB, Roach J, Siegel M, et al. A trial of church-based smoking cessation interventions for rural African Americans. Prev Med 1997;26:92-101.

74. Campion $\mathbf{P}$, Owen $\mathrm{L}, \mathrm{McNeill} \mathrm{A}$, et al. Evaluation of a mass media campaign on smoking and pregnancy. Addiction 1994;89:1245-54.

75. O'Loughlin JL, Paradis G, Gray-Donald K, et al. The impact of a community-based heart disease prevention program in a low-income, inner-city neighborhood. Am J Public Health 1999;89:1819-26.

76. Fisher EB, Auslander WF, Munro JF, et al. Neighbors for a smoke free north side: evaluation of a community organization approach to promoting smoking cessation among African Americans. Am J Public Health 1998;88:1658-63.

77. Hahn EJ, Rayens MK, Chirila C, et al. Effectiveness of a quit and win contest with a low-income population. Prev Med 2004;39:543-50.

78. Marin G, Perez-Stable EJ. Effectiveness of disseminating culturally appropriate smoking-cessation information: Programa Latino Para Dejar de Fumar. J Natl Cancer Inst Monogr 1995:155-63.

79. McAlister AL, Ramirez AG, Amezcua C, et al. Smoking cessation in Texas-Mexico border communities: a quasi-experimental panel study. Am J Health Promot 1992;6:274-9.

80. Wetter DW, Mazas C, Daza P, et al. Reaching and treating Spanish-speaking smokers through the National Cancer Institute's Cancer Information Service. A randomized controlled trial. Cancer 2007;109(2 Suppl):406-13.

81. Lipkus IM, Lyna PR, Rimer BK. Using tailored interventions to enhance smoking cessation among African-Americans at a community health center. Nicotine $\&$ Tobacco Research 1999;1:77-85.

82. Nevid J, Javier R. Preliminary investigation of a culturally specific smoking cessation intervention for Hispanic smokers. American Journal of Health Promotion 1997;11:198-207

83. Resnicow K, Vaughan R, Futterman $\mathrm{R}$, et al. A self-help smoking cessation program for inner-city African Americans: results from the Harlem health connection project. Health Education and Behavior 1997;24:201-17. 
84. Nelson DE, Gallogly M, Pederson LL, et al. Use of consumer survey data to target cessation messages to smokers through mass media. Am J Public Health 2008;98:536-42.

85. Farrelly MC, Hussin A, Bauer UE. Effectiveness and cost effectiveness of television, radio and print advertisements in promoting the New York smokers' quitline. Tob Control 2007:16(Suppl 1):i21-3.

86. Durkin S, Wakefield M. Comparative responses to radio and television anti-smoking advertisements to encourage smoking cessation. Health Promot Int 2010;25:5-13.

87. Kotler R, Roberto N, Lee N. Social marketing: Improving the quality of life. Thousand Oaks, CA: Sage, 2002.

88. del Pelsmacker $\mathbf{P}$. Advertising characteristics and the attitude towards the ad. Marketing and Research Today 1998;26:166-79.

89. Goldman LK, Glantz SA. Evaluation of antismoking advertising campaigns. JAMA 1998:279:772-7.

90. Donovan RJ, Boulter J, Borland R, et al. Continuous tracking of the Australian National Tobacco Campaign: advertising effects on recall, recognition, cognitions, and behaviour. Tob Control 2003;12(Suppl 2):ii30-9.

91. Biener L, Ji M, Gilpin EA, et al. The impact of emotional tone, message, and broadcast parameters in youth anti-smoking advertisements. J Health Commun 2004; 9:259-74.

92. Levy DT, Hyland A, Higbee $\mathrm{C}$, et al. The role of public policies in reducing smoking prevalence in California: results from the California tobacco policy simulation model. Health Policy 2007:82:167-85

93. Levy DT, Cho SI, Kim YM, et al. SimSmoke model evaluation of the effect of tobacco control policies in Korea: the unknown success story. Am J Public Health 2010;100:1267-73.

94. Levy DT, Mabry PL, Graham AL, et al. Reaching healthy people 2010 by 2013: a SimSmoke simulation. Am J Prev Med 2010;38(Suppl 3):S373-81.

95. Hurley SF, Matthews JP. Cost-effectiveness of the Australian national tobacco campaign. Tob Control 2008;17:379-84.
96. Thrasher JF, Huang L, Perez-Hernandez R, et al. Evaluation of a social marketing campaign to support Mexico City's comprehensive smoke-free law. Am J Public Health 2011;101:328-35.

97. Murukutla N, Turk T, Prasad CV, et al. Results of a national mass media campaign in India to warn against the dangers of smokeless tobacco consumption. Tob Control. Published Online First: 20 April 2011. doi:10.1136/tc.2010.039438

98. Cotter T, Hung WT, Perez D, et al. Squeezing new life out of an old sponge: how to modernise an anti-smoking media campaign to capture a new market. Aust N Z J Public Health 2011:35:75-80.

99. Cotter T, Perez D, Dunlop S, et al. The case for recycling and adapting anti-tobacco mass media campaigns. Tob Control 2010;19:514-17.

100. Brennan E, Durkin SJ, Cotter T, et al. Mass media campaigns designed to support new pictorial health warnings on cigarette packets: evidence of a complementary relationship. Tob Control 2011;20:412-18.

101. Borland $\mathbf{R}$, Yong $\mathrm{HH}$, Wilson $\mathrm{N}$, et al. How reactions to cigarette packet health warnings influence quitting: findings from the ITC Four-Country survey. Addiction 2009;104:669-75

102. Lieberman M. Social cognitive neuroscience. In: Fiske S, Gilbert D, Lindzey G, eds Handbook of Social Psychology. New York, NY: McGraw-Hill, 2010.

103. Durkin S, Wakefield M. Maximizing the impact of emotive antitobacco advertising: effects of interpersonal discussion and program placement. Soc Market 0 2006;12:3-14.

104. Durkin S, Wakefield M. Interrupting a narrative transportation experience: program placement effects on responses to anti-smoking advertising. J Health Commun 2008;13:667-80.

105. Chang FC, Chung $\mathrm{CH}$, Chuang YC, et al. Effect of media campaigns and smoke-free ordinance on public awareness and secondhand smoke exposure in Taiwan. $J$ Health Commun 2011:16:343-58.

106. World Health Organization. WHO Framework Convention on Tobacco Control. 2003. http://whqlibdoc.who.int/publications/2003/9241591013.pdf (accessed 2010 July 24). 